\title{
Infectividade de juvenis do segundo estádio de Meloidogyne incognita em tomateiro após privação alimentar em solo e água em diferentes condições
}

\author{
Eduardo Souza Freire ${ }^{1}$, Vicente Paulo Campos ${ }^{1}$, Marcos Roberto Dutra ${ }^{2}$, Fernando da Silva Rocha ${ }^{1}$, Juliana Resende \\ Campos da Silva ${ }^{3} \&$ Edson Ampélio Pozza ${ }^{1}$
}

${ }^{1}$ Universidade Federal de Lavras-UFLA, Departamento de Fitopatologia, C.P. 3037, CEP 37200-000, Lavras-MG, Brasil. E-mail: esfreire26@yahoo.com.br; 2Syngenta Proteção de Cultivos Ltda, CEP 38408-188, Uberlândia-MG, e-mail: marcos.dutra@syngenta.com.br; ${ }^{3}$ Universidade de Rio Verde, Departamento de Agronomia, C.P. 104, CEP 75901-970, Rio Verde-GO, Brasil, e-mail: jrcampos@fesurv.br. Autor (a) para correspondência: Fernando S. Rocha

Data de chegada: 29/09/2005. Aceito para publicação em: 06/12/2006.

\section{RESUMO}

Freire, E. S.; Campos, V. P.; Dutra, M. R.; Rocha, F. S.; Silva, J. R. C. Pozza, E. A. Infectividade de juvenis do segundo estádio de Meloidogyne incognita em tomateiro após privação alimentar em solo e água em diferentes condições. Summa Phytopathologica, v.33, n.3, p.270-274, 2007.

O juvenil do segundo estádio (J2) de Meloidogyne spp. gasta sua reserva energética corporal de formas diferentes sob condições variadas de temperatura e umidade do solo, chegando à incapacidade de parasitismo vegetal. Desta forma, objetivou-se neste trabalho estudar o efeito da incubação de $\mathrm{J} 2$ de $M$. incognita em solo com níveis de umidade e temperaturas diferentes, além do borbulhamento da suspensão do inóculo na infectividade desses J2 em tomateiro. A infectividade dos $\mathrm{J} 2$ armazenados no solo em tomateiros decresceu significativamente entre as temperaturas estudadas durante o período de seis dias. Maior $(\mathrm{P}<0,01)$ infectividade ocorreu com $\mathrm{J} 2$ armazenados no solo a $8{ }^{\circ} \mathrm{C}$ e menor a $28{ }^{\circ} \mathrm{C}$. Também o decréscimo da umidade do solo de $30 \%$ para $5 \%$ causou redução significativa na infectividade. Dentre as temperaturas do solo estudadas, apenas a $28{ }^{\circ} \mathrm{C}$ ocorreu redução da infectividade, quando se usou solo seco comparado com o úmido, chegando a aproximadamente $98 \%$ de redução a partir de 4 dias de armazenamento. A imobilização dos J2 mantidos em água aumentou com o período de armazenamento, com o aumento da temperatura e com o borbulhamento da água. A infectividade dos $\mathrm{J} 2$ armazenados na água decresceu com o aumento da temperatura e com o borbulhamento, porém a $8{ }^{\circ} \mathrm{C}$ o borbulhamento não afetou a imobilização dos J2.

Palavras-chave adicionais: Teor de lipídios, parasitismo radicular, nematóide de galhas, reprodução de nematóide.

\begin{abstract}
Freire, E. S.; Campos, V. P.; Dutra, M. R.; Rocha, F. S.; Silva, J. R. C.; Pozza, E. A. Infectivity of second stage juveniles of Meloidogyne incognita in tomato after starvation in soil and water at different conditions. Summa Phytopathologica, v.33, n.3, p.270-274, 2007.

The second stage juvenile (J2) of Meloidogyne spp. spend the storaged energy of the body, differently, when living in variable conditions of soil temperatures and humidities approaching to the incapability of plant parasitism. Therefore, the aim of this work was to study the storage of J2 of $M$. incognita in soil at different levels of humidity and temperature, besides water bubbling of inoculum suspension on the infectivity of starved J2 in tomato. The infectivity of $\mathrm{J} 2$ in tomato decreased significantly among storaged temperatures during the period of six days in soil. Greatest $(\mathrm{P}<0,01)$ infectivity occurred when $\mathrm{J} 2$ was storaged at 8

${ }^{\circ} \mathrm{C}$ and least at $28{ }^{\circ} \mathrm{C}$. When soil humidity decreased from $30 \%$ to $5 \%$ the $\mathrm{J} 2$ infectivity was significantly reduced. Among all storaged temperatures tested, only at $28{ }^{\circ} \mathrm{C}$ occurred reduction of $\mathrm{J} 2$ infectivity in dry soil (5\%) compared to humid (30\%), approaching to $98 \%$ reduction from 4 days storage of $\mathrm{J} 2$. When $\mathrm{J} 2$ was storaged in water, its mobility decreased along the storage period, following the same trend with the temperature and water bubbling increased. The infectivity of $\mathrm{J} 2$ storaged in water decreased as the temperature and the water bubbling increased. However at $8{ }^{\circ} \mathrm{C}$ the water bubbling did not affect the $\mathrm{J} 2$ mobility.
\end{abstract}

Additional Keywords: lipid content, root parasitism, root-knot nematode, nematode reproduction.

O juvenil do segundo estádio (J2) de Meloidogyne constitui a forma infectiva em plantas. No processo de parasitismo estão envolvidas diversas etapas: atração do juvenil pela planta, penetração pela região meristemática da raiz, movimentação dentro do hospedeiro e identificação do local receptivo do elicitor, além da excreção dos produtos da glândula esofagiana dorsal, reconhecimento do elicitor pela planta e formação das células gigantes (7). Portanto, o sucesso do parasitismo do $\mathrm{J} 2 \mathrm{em}$ plantas envolve o cumprimento de todas essas etapas, o que demanda energia e condições fisiológicas adequadas. A energia necessária está, principalmente, no conteúdo lipídico corporal acumulado durante o desenvolvimento embrionário (9), que deve ser suficiente para o juvenil eclodir e cumprir, com sucesso, todas as 
etapas do processo de parasitismo. A prolongada ausência de hospedeiro no campo leva o J2 a usar sua reserva para movimentação pelo solo, a qual é afetada pela temperatura e umidade do solo (9). Segundo Van Gundy et al. (12), se o J2 gastar mais de 50\% das reservas lipídicas corporais, não terá mais capacidade de infectar a planta.

O tempo de duração da fase infectiva do $\mathrm{J} 2$ no solo varia com a adaptação da espécie ao ambiente em que vive e é também importante para se definir a duração do alqueive. Dutra \& Campos $(3,4)$ e Dutra et al. (5) demonstraram a eficácia do alqueive de 14 dias após o manejo do solo e da irrigação no campo antes do plantio de alface, feijão ou quiabo na redução populacional de Meloidogyne spp. porém, não explicaram o processo envolvido. Desta forma, objetivou-se neste trabalho estudar o efeito do tempo de duração do período de privação alimentar de $\mathrm{J} 2$ em condições diferentes de temperatura, umidade do solo e oxigenação da água na infectividade de $M$. incognita em tomateiro.

\section{MATERIAL E MÉTODOS}

Efeito do armazenamento de juvenis do segundo estádio de Meloidogyne incognita em solo sob diferentes teores de umidade e temperaturas na infectividade em tomateiro

Ovos de M. incognita (Kofoid \& White, 1919) Chitwood, 1949, raça 3 foram extraídos de raízes de tomateiros (Lycopersicon esculentum Mill. cv. Santa Clara) mantidos em casa-de-vegetação, utilizando-se a técnica de Hussey \& Barker (8). Para obter os J2, utilizou-se câmara de eclosão formada com tela e papel de espessura fina, colocados em funil de vidro. Foram utilizados nos ensaios apenas os J2 eclodidos no terceiro dia de incubação dos ovos.

Copo plástico de $200 \mathrm{~mL}$ de volume, com $150 \mathrm{~g}$ de solo peneirado proveniente de área experimental da Fazenda Gameleira (4), situada no município de Lagoa Grande, na região do Alto Paranaíba, $\mathrm{MG}$, classificado como neossolo quartzarênico, com $86 \%$ de areia, $1 \%$ de silte e $13 \%$ de argila e autoclavado por $2 \mathrm{~h}$ a $120{ }^{\circ} \mathrm{C}$, em dois ciclos intercalados de resfriamento, constituiu a unidade experimental. Com o intuito de explicar o processo envolvido nos resultados obtidos por Dutra \& Campos (4) no controle de M. incognita em feijoeiro no campo por meio do manejo do solo e da irrigação, utilizou-se o mesmo solo da área experimental, porém sob condições controladas de temperatura e umidade. Para isto, no centro deste copo com o solo colocou-se um molde de gesso revestido por parafina no mesmo

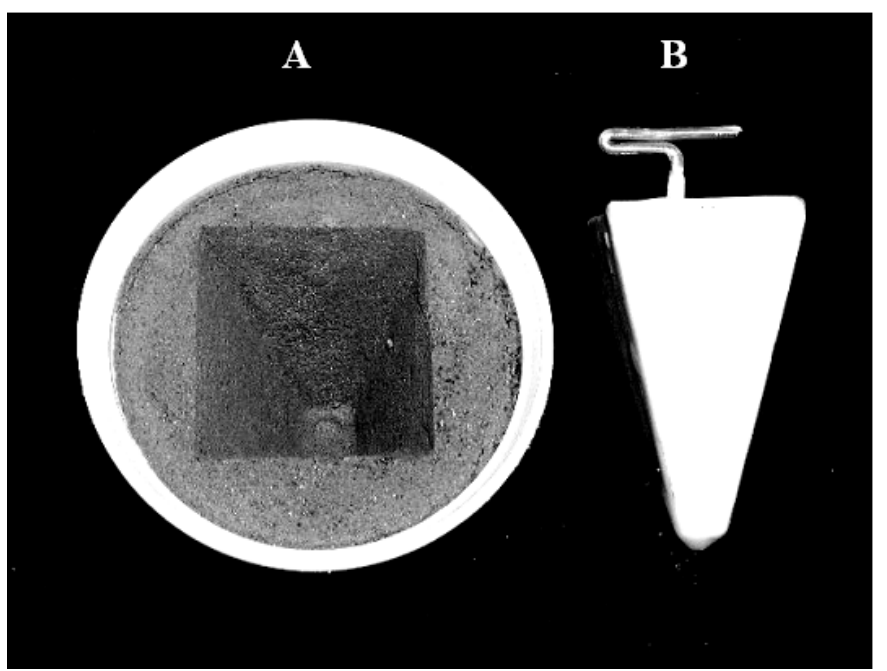

Figura 1. Vista de topo da superfície do copo onde estava imerso o molde (A) e o molde de gesso separadamente (B). formato, tamanho e volume (Figura 1) das células da bandeja de isopor, onde mudas de tomateiros estavam sendo cultivadas para uso neste ensaio. Em cada copo com solo, $2.000 \mathrm{~J} 2$ dispersos em $4 \mathrm{~mL}$ de água foram colocados em 4 furos de $\pm 5 \mathrm{~mm}$ de diâmetro feitos, com o auxílio de um bastão de vidro, na profundidade de $\pm 3 \mathrm{~cm}$ ao redor do molde de gesso. Na testemunha, logo após a infestação, trocaram-se os moldes de gesso por mudas de tomateiro cv. Santa Clara com 30 dias, a contar da semeadura e os copos foram colocados em sala climatizada a $28 \pm 2{ }^{\circ} \mathrm{C}$ e mantida a umidade do solo a $30 \%$. Os demais copos com solo e infestados por $\mathrm{J} 2$ foram colocados em bandejas e divididos em 3 grupos. Cada um foi incubado em uma das temperaturas: $8 \pm 1{ }^{\circ} \mathrm{C}, 18 \pm 1^{\circ} \mathrm{C}$ ou $28 \pm 2{ }^{\circ} \mathrm{C}$. As temperaturas foram monitoradas por sensores colocados dentro dos copos, conectados por cabos, a "datallogers" (Davis). Em cada temperatura, metade do número de copos foi mantida a $30 \%$ de umidade, e a outra, a $5 \%$ de umidade do solo, com correção em peso feita diariamente com água destilada. Aos 2, 4 ou 6 dias após, retiraram-se os moldes de gesso e, sem causar distúrbio no solo ao redor, foi transplantada muda de tomateiro para o mesmo local. A seguir, os copos contendo as mudas transplantadas foram levados para sala climatizada onde estavam as testemunhas, com temperatura mantida a $28 \pm 2{ }^{\circ} \mathrm{C}$, condições propícias para o teste de patogenicidade do inóculo no solo. O ensaio foi estabelecido num delineamento experimental inteiramente casualizado em esquema fatorial de $4 \times 3 \times 2$, sendo 4 períodos de privação alimentar, 3 temperaturas do solo e 2 níveis de umidade, em 10 repetições.

Vinte dias após o transplantio das mudas de tomate, cortou-se a parte aérea. As raízes foram separadas do solo em água parada e avaliado o número de galhas por sistema radicular. A seguir, todo o sistema radicular foi colocado por 15 min., numa solução com $0,0015 \%$ de Floxina B que coloriu de vermelho as massas de ovos dos nematóides. As raízes foram então deixadas por $10 \mathrm{~min}$. sobre papel toalha para possibilitar a avaliação do peso da matéria fresca das raízes, seguido da contagem do número de massas de ovos por sistema radicular. $\mathrm{O}$ sistema radicular foi, então, cortado em pedaços de aproximadamente $1 \mathrm{~cm}$ para extração de ovos pela técnica de Hussey \& Barker (8). No microscópio de objetiva invertida, estimou-se o número de ovos de $M$. incognita por sistema radicular.

As variáveis significativas pelo teste $\mathrm{F}$ foram submetidas a análise de regressão para ajuste do melhor modelo, quando quantitativo, e ao teste de médias de Scott \& Knott (11), quando qualitativo. As análises foram realizadas pelo programa estatístico SISVAR.

Efeito do armazenamento de juvenis do segundo estádio de Meloidogyne incognita mantidos em água borbulhada e parada sob diferentes temperaturas e períodos na infectividade em tomateiro

Neste ensaio, os $\mathrm{J} 2$ foram armazenados em água parada ou com borbulhamento por 2,4 ou 6 dias, em temperaturas de 8,18 ou $28^{\circ} \mathrm{C}$, monitoradas por sensores conectados a "datallogers", seguido do teste de patogenicidade em tomateiros.

Foram empregadas mudas de tomateiro (Lycopersicon esculentum Mill. cv. Santa Clara) produzidas a partir da semeadura em bandejas de isopor com 72 células e substrato agrícola Plantmax ${ }^{\circledR}$. Cada muda constituiu uma unidade experimental. O ensaio foi estabelecido num delineamento inteiramente casualizado, organizado em fatorial de $4 \mathrm{x}$ $3 \times 2$, sendo 4 períodos de incubação, 3 temperaturas e 2 condições de oxigenação da água, em 10 repetições.

Após cada período de armazenamento ( $0,2,4$ ou 6 dias), nas diferentes temperaturas, $2.000 \mathrm{~J} 2$ foram inoculados em mudas de tomateiro, com 30 dias a partir da semeadura. Na inoculação, os J2 
foram dispersos em $4 \mathrm{~mL}$ de água, colocados em furos de $\pm 5 \mathrm{~mm}$ de diâmetro feitos com o auxílio de um bastão de vidro junto ao caule da muda. A cada inoculação, fez-se avaliação prévia da mobilidade dos J2 em água. Os J2 foram considerados inativos quando não se movimentavam ou quando apresentavam o corpo com aspecto retilínio ou retorcido. Espécimens que permaneceram inativos após 12 horas em água, foram classificados como mortos. As mudas inoculadas foram mantidas em casa-de-vegetação própria para a produção de hortaliças com umidade controlada via irrigação por nebulização, portanto em condições propícias para o teste de patogenicidade.

Vinte dias após a inoculação, avaliou-se o número de galhas por sistema radicular do tomateiro.

Os dados obtidos nos ensaios foram transformados em $\sqrt{x+0,5}$. Fez-se a análise de regressão para o período de incubação. Os fatores temperatura e condições de armazenamento foram agrupados pelo teste de Scott \& Knott (11). As análises foram realizadas pelo mesmo programa estatístico mencionado no ensaio anterior.

\section{RESULTADOS E DISCUSSÃO}

Efeito do armazenamento de juvenis do segundo estádio de Meloidogyne incognita em solo sob diferentes teores de umidade e temperaturas na infectividade em tomateiro

Não houve interação entre os fatores períodos de incubação, temperatura e umidade do solo na infectividade de $\mathrm{J} 2$ de $M$. incognita
Tabela 1. Número médio de galhas por sistema radicular de tomateiro após diferentes períodos de armazenamento de juvenis do segundo estádio (J2) de Meloidogyne incognita raça $3 \mathrm{em}$ solo úmido ou seco a $28^{\circ} \mathrm{C}$.

\begin{tabular}{llcc}
\hline & \multicolumn{3}{c}{ Período de armazenamento (dias) } \\
Tratamentos & 2 & 4 & 6 \\
Solo úmido & $312 \mathrm{a}$ & $247 \mathrm{a}$ & $141 \mathrm{a}$ \\
Solo seco & $182 \mathrm{~b}$ & $4 \mathrm{~b}$ & $1 \mathrm{~b}$ \\
\hline
\end{tabular}

Em cada coluna, médias seguidas de letras distintas são diferentes, estatisticamente, entre si pelo teste $\mathrm{F}$ a $1 \%$ de probabilidade.

em tomateiro. Entretanto, a infectividade dos J2 decresceu significativamente durante o período de seis dias de armazenamento no solo neossolo quartzarênico de textura arenosa (Figuras 2A, 3A e $4 \mathrm{~A})$. Esse decréscimo na infectividade, contudo, foi diferenciado $(\mathrm{P} \leq 0,01)$ entre as temperaturas de armazenamento. A maior infectividade ocorreu a $8{ }^{\circ} \mathrm{C}$ e a menor a $28^{\circ} \mathrm{C}$ (Figuras $2 \mathrm{~B}, 3 \mathrm{~B}$ e $4 \mathrm{~B}$ ). Também o decréscimo da umidade do solo de $30 \%$ para $5 \%$ causou redução significativa na infectividade (Figuras 2C, 3C e 4C). Quando se analisou o efeito da redução da umidade em cada temperatura de armazenamento, apenas a $28^{\circ} \mathrm{C}$ a redução da umidade do solo para $5 \%$ (solo seco) diminuiu significativamente a infectividade dos J2 em todos os períodos de armazenamento chegando a quase nula a partir do quarto dia de armazenamento a $5 \%$ de umidade (Tabela 1 ).

Comparando-se os três parâmetros empregados na avaliação da infectividade do inóculo de $\mathrm{J} 2$ estocado durante seis dias no solo,
A

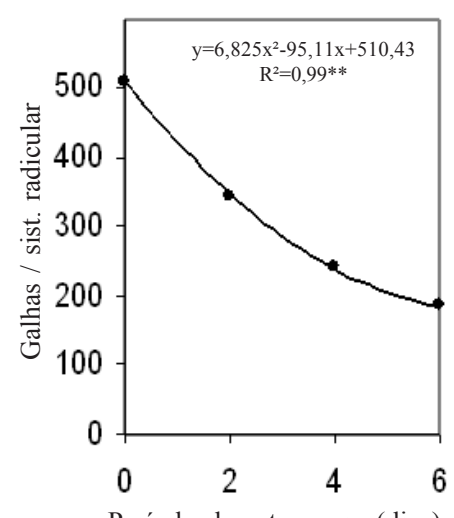

Período de estocagem (dias)

A

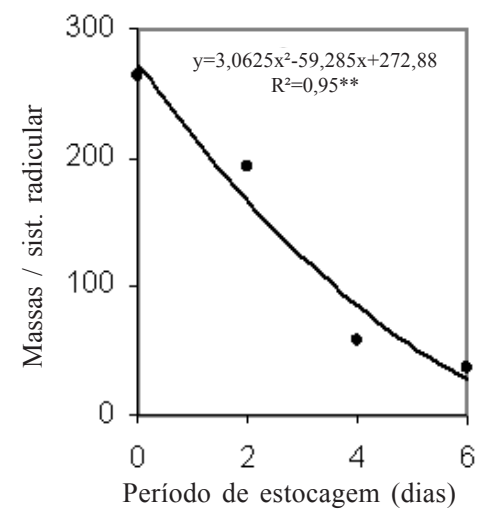

B

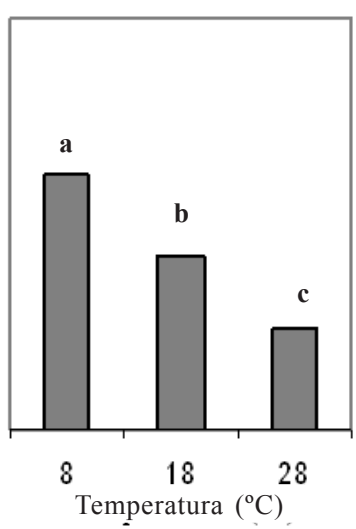

B

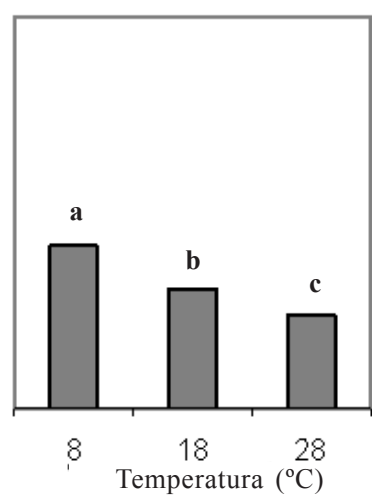

C

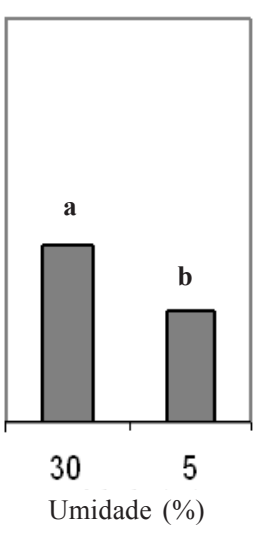

Figura 2. Efeito de períodos de armazenamento de juvenis do segundo estádio (J2) de Meloidogyne incognita raça $3 \mathrm{em}$ diferentes temperaturas e umidades do solo no número de galhas por sistema radicular de tomateiro. A) regressão do período de privação alimentar, B) temperatura, C) umidade do solo no armazenamento dos J2. Barras seguidas pela mesma letra não diferem, significativamente, entre si pelo teste de Scott \& Knott (11), a 1\% de probabilidade.

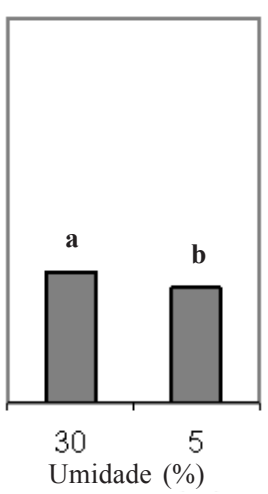

Figura 3. Efeito de períodos de armazenamento de juvenis do segundo estádio (J2) de Meloidogyne incognita raça 3 em diferentes temperaturas e umidades do solo no número de massas de ovos por sistema radicular de tomateiro. A) regressão do período de privação alimentar, B) temperatura, C) umidade do solo no armazenamento dos J2. Barras seguidas pela mesma letra não diferem, significativamente, entre si pelo teste de Scott \& Knott (11), a $1 \%$ de probabilidade. 


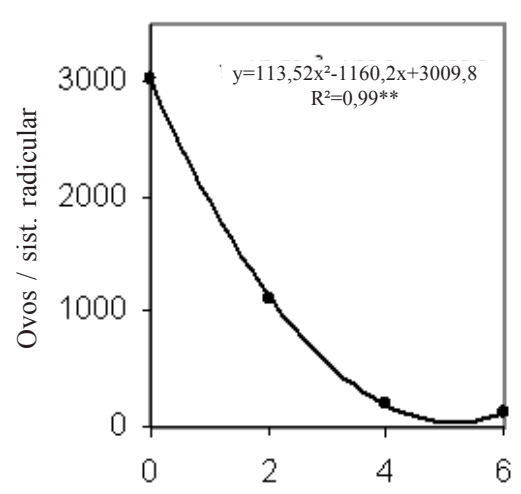

Período de estocagem (dias)

A

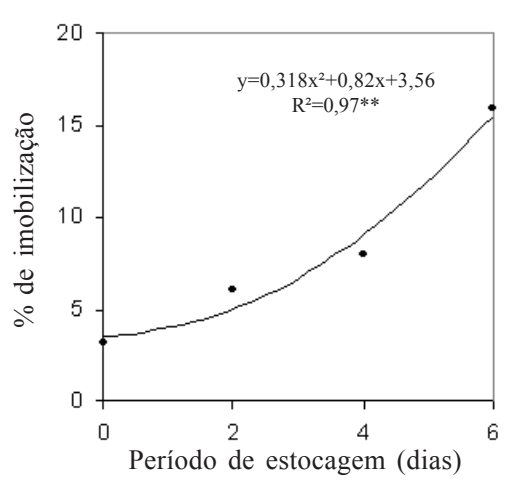

A

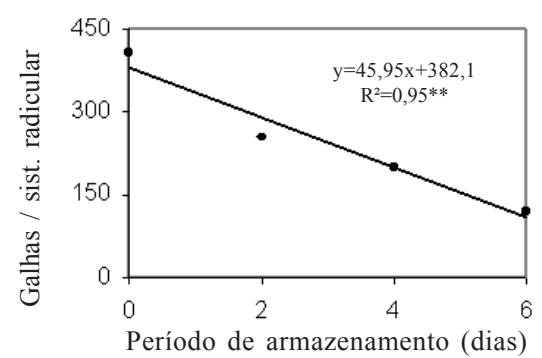

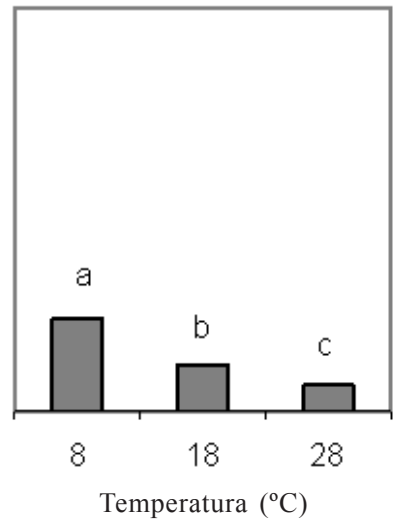

B

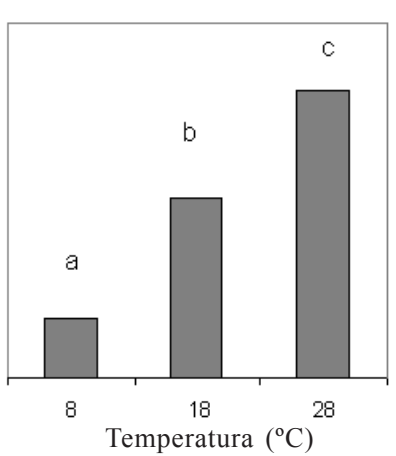

B

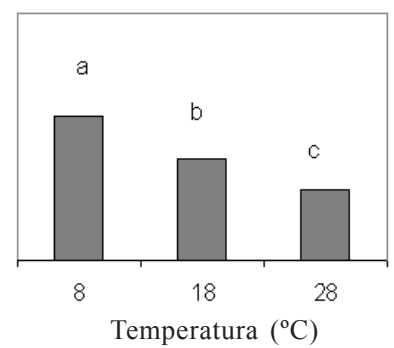

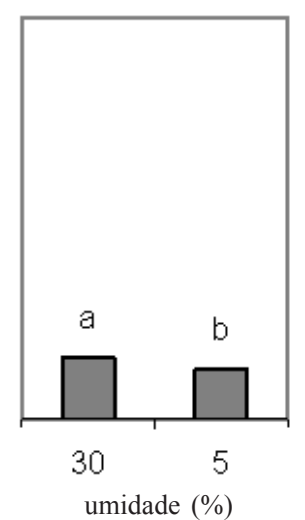

C

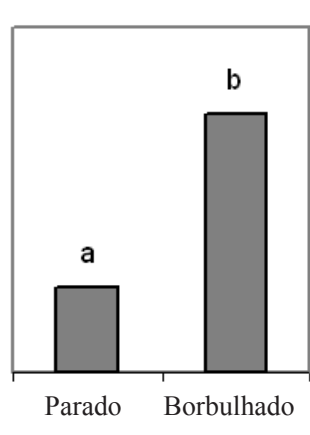

C

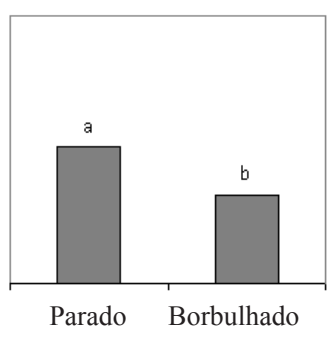

Figura 4. Efeito de períodos de armazenamento de juvenis do segundo estádio (J2) de Meloidogyne incognita raça 3 em diferentes temperaturas e umidades do solo no número de ovos por sistema radicular de tomateiro. A) regressão do período de privação alimentar, B) temperatura, C) umidade do solo no armazenamento dos J2. Barras seguidas pela mesma letra não diferem, significativamente, entre si pelo teste de Scott \& Knott (11), a 1\% de probabilidade.
Figura 5. Percentagem total de imobilização de juvenis do segundo estádio (J2) de Meloidogyne incognita raça 3 armazenados em água: A) regressão do período de privação alimentar, B) temperatura de armazenamento, C) borbulhamneto ou não da água usada no armazenamento. Barras seguidas pela mesma letra não diferem, significativamente, entre si pelo teste de Scott \& Knott (11), a $1 \%$ de probabilidade. observou-se efeito mais drástico do período de armazenamento na redução da reprodução de $M$. incognita do que na formação de galhas (Figuras 2A,B e C; 3A,B e C; 4A,B e C).

A maior infectividade dos $\mathrm{J} 2$ armazenados a $8^{\circ} \mathrm{C}$ (Figuras 2B, 3B e 4B) muito provavelmente significa que essa temperatura não causou injúrias e levou a diminuição dos movimentos do J2 no solo, preservando assim as reservas energéticas corporais, que foram empregadas no parasitismo das raízes. Van Gundy et al. (12) não encontraram diferenças no conteúdo lipídico e de proteína corporal de $\mathrm{J} 2$ de $M$. javanica armazenados durante 4 dias a 5 e $15^{\circ} \mathrm{C}$. Bergerson (1) verificou que a $10^{\circ} \mathrm{C}$ o J2 de $M$. incognita tem baixo metabolismo e utiliza pouco a sua reserva. Goodell $\&$ Ferris (6) encontraram baixa mobilidade de $\mathrm{J} 2$ de $M$. incognita a $10{ }^{\circ} \mathrm{C}$. Contudo, no ensaio aqui apresentado, o gasto energético e o aumento dos movimentos do $\mathrm{J} 2$ no solo foram, muito provavelmente, proporcionais ao aumento da temperatura de $18{ }^{\circ} \mathrm{C}$ para $28^{\circ} \mathrm{C}$ reduzindo assim a energia disponível para o parasitismo, o que resultou em queda significativa da infectividade (Figuras 2B, 3B e 4B). Prot \& Van Gundy (10) observaram $2 \%$ de migração vertical de $\mathrm{J} 2$ de $M$. incognita para raízes de tomateiro a temperatura de $18{ }^{\circ} \mathrm{C}$ e de $30 \%$ entre 20 e $22{ }^{\circ} \mathrm{C}$. Van Gundy et al. (12) encontraram redução significativa no conteúdo lipídico e de proteína corporal de $\mathrm{J} 2$ de $M$. javanica armazenados durante 4 dias a partir de $25^{\circ} \mathrm{C}$, porém a infectividade só foi reduzida a $35^{\circ} \mathrm{C}$.

A alta queda na infectividade dos $\mathrm{J} 2$ incubados a $28^{\circ} \mathrm{C}$ e em solo seco ( $5 \%$ de umidade) ao que tudo indica envolve morte do juvenil por dessecação em algum nicho do solo devido a alta movimentação provocada pela alta temperatura do solo $\left(28^{\circ} \mathrm{C}\right)$ ou então pelo maior gasto energético requerido pelo solo seco comparado com o úmido, 
como concluiu Van Gandy et al. (12) nos seus ensaios. Dutra \& Campos $(3,4)$ e Dutra et al. $(5)$ testaram o revolvimento do solo e a irrigação em condições de campo sempre com temperatura elevada e baixa umidade do ar, obtendo excelente redução do nível populacional de Meloidogyne spp. Como neste ensaio usou-se o mesmo solo do local do experimento em que Dutra \& Campos (4) realizaram o revolvimento e irrigação do solo, 14 dias antes da semeadura do feijoeiro e reduziram significativamente a população de $M$. incognita, significa que o período de 14 dias de alqueive foi plenamente suficiente para incapacitar os J2 livres no solo de parasitar as raízes do feijoeiro no campo. Portanto a privação alimentar por 4 a 6 dias a temperatura de $28^{\circ} \mathrm{C}$ e umidade do solo de $5 \%$ leva a redução drástica dos $\mathrm{J} 2$ do solo.

Efeito do armazenamento do juvenil do segundo estádio de Meloidogyne incognita mantidos em água borbulhada e parada sob diferentes temperaturas e períodos na infectividade em tomateiro

Não houve interação entre os fatores períodos de armazenamento, temperatura e oxigenação da água na infectividade em tomateiro dos J2 de $M$. incognita armazenados em água. Entretanto, a imobilização do J2 aumentou com o período de armazenamento, com o aumento da temperatura e com o borbulhamento da água (Figuras 5A, B e C). As diferenças foram significativas em cada temperatura estudada, com menor $(\mathrm{P}<0,01)$ número de $\mathrm{J} 2$ imobilizado a $8{ }^{\circ} \mathrm{C}$ de armazenamento e o maior a $28{ }^{\circ} \mathrm{C}$ (Figura 5B). Quando se analisou o efeito do borbulhamento em cada temperatura, observou-se que apenas o armazenamento dos $\mathrm{J} 2$ a $8{ }^{\circ} \mathrm{C}$ o borbulhamento não afetou a porcentagem de imobilização.

A infectividade dos $\mathbf{J} 2$ armazenados em água, expressa em galhas por sistema radicular do tomateiro, diminuiu com o aumento do período de armazenamento, decresceu com o aumento da temperatura e com o borbulhamento da água (Figuras 6A, B e C). Esse decréscimo na infectividade, contudo, foi diferenciado $(\mathrm{P}<0,01)$ entre as temperaturas da água. Maior $(\mathrm{P}<0,01)$ infectividade ocorreu quando os $\mathrm{J} 2$ foram armazenados a $8{ }^{\circ} \mathrm{C}$ e a menor $(\mathrm{P}<0,01)$ a $28^{\circ} \mathrm{C}$ (Figura $6 \mathrm{~B}$ ).

Neste ensaio em que os $\mathrm{J} 2$ foram armazenados em água o decréscimo na infectividade e o aumento da imobilização dos J2 com o aumento do período de armazenamento, temperatura e com o borbulhamento, à semelhança do ensaio anterior, ao que tudo indica, está relacionado a perda da reserva energética corporal do J2. A atividade muscular e a temperatura alta aumentam a perda da reserva lipídica (12). Campos (2) observou perda de 56,12\% do teor de lipídio corporal em $\mathrm{J} 2$ de $M$. javanica aos 4 dias de armazenamento em água parada a $28^{\circ} \mathrm{C}$, o que proporcionou redução acentuada na penetração, no número de fêmeas, massas de ovos e de ovos. Goodell \& Ferris (6) relataram que a $29^{\circ} \mathrm{C}$, a atividade muscular requer grande utilização de energia, além da manutenção da respiração.

Bergerson (1) verificou que $10{ }^{\circ} \mathrm{C}$ se aproxima do ponto ótimo para a sobrevivência de ovos e de $\mathrm{J} 2$ de $M$. incognita por causa do baixo metabolismo e da pequena utilização das reservas energéticas. Portanto, o borbulhamento da água em temperaturas de 18 e $28{ }^{\circ} \mathrm{C}$ concorrem para a imobilização do J2 e perda da infectividade.

\section{REFERÊNCIAS BIBLIOGRÁFICAS}

1. Bergerson, G. B. The influence of temperature on the survival of some species of the genus Meloidogyne in the absence of a host. Nematologica, Leiden, v.4, n.4, p.344-354, 1959.

2. Campos, H. D. Aspectos do parasitismo e da privação alimentar do nematóide de galhas (Meloidogyne javanica) e do cisto (Heterodera glycines) em soja. 2003. 203p. Tese (Doutorado em Fitopatologia) - Universidade Federal de Lavras, Lavras.

3. Dutra, M. R.; Campos, V. P. Efeito do manejo de solo e da água na população de Meloidogyne javanica em quiabeiro no campo. Summa Phytopathologica, Botucatu, v.29, n.3, p.249-254, $2003 \mathrm{a}$.

4. Dutra, M. R.; Campos, V. P. Manejo do solo e da irrigação como nova tática de controle de Meloidogyne incognita em feijoeiro. Fitopatologia Brasileira, Brasília, v.28, n.6, p. 608-614, 2003b.

5. Dutra, M. R.; Campos, V. P.; Toyota, M. Manejo do solo e da irrigação para o controle de Meloidogyne javanica em alface. Nematologia Brasileira, Brasília, v.27, n.1, p.29-34, 2003.

6. Goodell, P. B.; Ferris, H. Influence of environmental factors on the hatch and survival of Meloidogyne incognita. Journal of Nematology, Lawrence, v.21, n.3, p.328-334, 1989.

7. Hussey, R. S.; Grundler, F. W. Nematode parasitism of plants In: Perry, R. N.; Wright, D. J. (Ed.). The physiology and biochemistry of free-living and plant-parasitic nematodes. Wallingford: CABI, 1998. p. 213-243.

8. Hussey, R. S.; Barker, K. R. A comparison of methods of collecting inocula for Meloidogyne spp., including a new technique. Plant Disease Reporter, St. Paul, v.57, n.12, p. 1025-1028, 1973.

9. Lee, D. L.; Atkinson, H. J. Physiology of nematodes. New York: Columbia University, 1977. 215p.

10. Prot, J. C.; Van Gundy, S. D. Influence of photoperiod and temperature on migrations of Meloidogyne juveniles. Journal of Nematology, Lakekand, v.13, n.2, p.217-220, 1981.

11. Scott, A. J.; Knott, M. Cluster analysis method for grouping means in the analysis of variance. Biometrics, London, v.30, n.3, p.507-512, 1974.

12. Van Gundy, S. D.; Bird, A. F.; Wallace, H. R. Aging and starvation in juvenile of Meloidogyne javanica and Tylenchulus semipenetrans. Phytopathology, St. Paul, v.57, n.6, p.559-571, 1967. 